DOI: $10.2478 /$ lpts-2018-0023

\title{
SYNCHRONIZATION OF NON-LINEAR DYNAMIC SYSTEMS UNDER THE CONDITIONS OF NOISE ACTION IN THE CHANNEL
}

\author{
O. Golevych ${ }^{1}$, O. Pyvovar ${ }^{2}$, P. Dumenko ${ }^{3}$ \\ ${ }^{1 \& 3}$ DiGas Ltd. \\ 31 Talsu soseja, K-17-34, Jurmala, LV-2016, LATVIA \\ e-mail11: oleg_plus@mail.ru \\ e-mail'3 : p.dumenko@digasgroup.com \\ ${ }^{2}$ Khmelnytskyi National University \\ 11 Instytutska Str., 29016, Khmelnytskyi, UKRAINE \\ e-mail: opyvovar2@gmail.com
}

\begin{abstract}
Areas of optimal amplitudes and minimal spectral unevenness of Rucklidge chaotic signals with better correlation abilities are demonstrated in the present research. A model of chaotic synchronization and information transmission system is implemented. The effect of the synchronization feedback coefficient and signal-to-noise ratio on the systems noise immunity is shown.
\end{abstract}

Keywords: chaos, non-uniformity of the signal spectrum, Rucklidge, SNR, spectrum width, synchronization

\section{INTRODUCTION}

Due to telecommunication systems development and radio frequency loading, as well as along with the need to ensure high speed and interference immunity, much attention is paid to the investigation of signal-code structures based on deterministic chaos signals. Signals of deterministic chaos have specific features that make it possible to separate them into a separate group of signals that are extremely promising in the role of channel subcarriers: broadband; complexity; orthogonality.

Ideally, the synchronization of deterministic chaos oscillators (DCG) [1]-[4] implies the simultaneity and uniformity of the evolution of the phase trajectories of spatially separated nonlinear dynamic system (NDS), a similar type of synchronization is called complete. The most common is a one-way synchronization type from the master oscillator to the slave. Investigations of bi-directional synchronization lead to unpredictable results as a result of competition between two modes of chaotic fluctuations.

If the structure of the associated NDS oscillators is the same, but there is some difference between the control parameters of the slave and master systems, by selecting other parameters and characteristics it is possible to provide a deterministic 
relationship between the phase trajectories of the leading and slave oscillators. This similar synchronization type is called generalized.

\section{DYNAMIC SYSTEM SELECTION AND ITS PARAMETER ANALYSIS}

\subsection{Dynamic Systems Evaluation Criteria}

NDS of a certain structure can generate signals of different types, if it is possible to receive chaotic oscillations and such NDS describe some real process, then the oscillator gets its own name. Each such DCG has a range of values of initial conditions and control parameters that allow receiving signals of deterministic chaos.

To separate the input values of the dynamic system, in which only chaotic signals are generated, it is necessary to prove the linear independence of the group consisting of a series of realizations of the chaotic signal taken at different time intervals, i.e., to calculate their mutual correlation characteristics [5]. Due to the nonperiodicity of the chaotic signal, the realizations form a linearly independent basis. In an ideal case, implementations in a group must be pairwise orthogonal.

Based on the results of the analysis [6], [7] for the construction of a communication system, it is advisable to use the Rucklidge NDS, whose signals in the majority of estimates have better spectral and correlation properties than other NDS.

\subsection{Rucklidge Oscillator Signal Statistics}

Rucklidge oscillator is described with a system of three nonlinear differential equations [8]. The results of the distribution analysis of the gramian $\mathrm{G}$ values [6] and the spectral nonuniformity $\Delta N_{S}$ from the values of the control parameters $K$ and $L$ (Fig. 1) make it possible to isolate the range of generation parameters of the deterministic chaos, which is extremely wide for this oscillator, that allows varying the parameters during the construction of a chaotic telecommunication system.
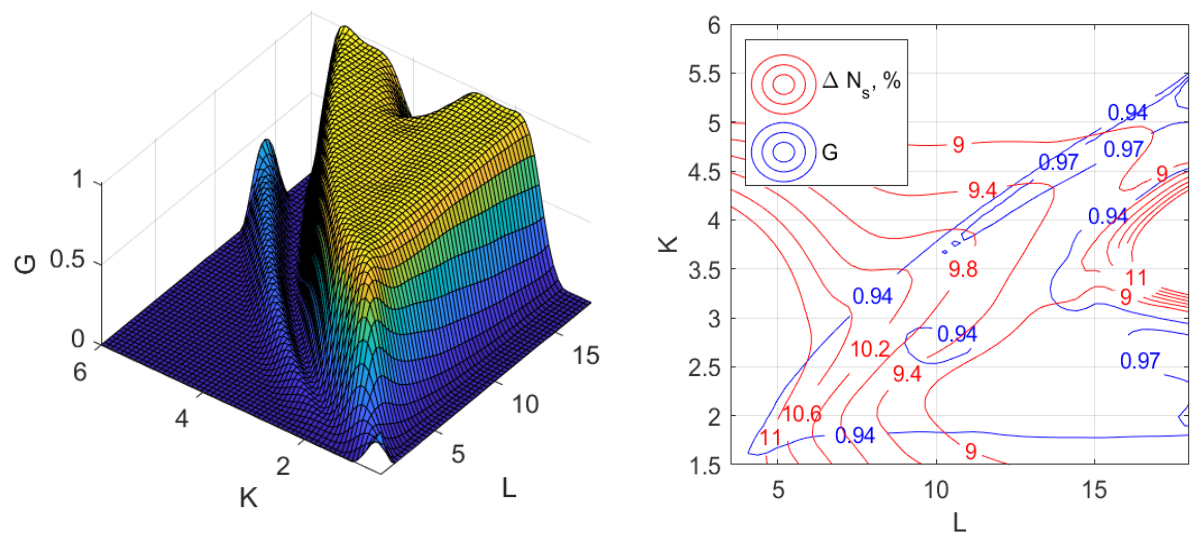

Fig. 1. Distribution gramian values $(\mathrm{G})$ (left) and distribution of the gramian values $\mathrm{G}$ and spectral nonuniformity values $\Delta N_{s}$ (right). 
In order to find the regions of the parameters of the incoming values of $K$ and $L$ at which the Rucklidge system generates chaotic signals with a high degree of orthogonality and minimal spectrum unevenness, a criterion was used according to which values of $K$ and $L$ the determinant of the Gram matrix composed of DCS realizations would be above 0.9 (full range gramian distribution shown in Fig. 1).

Choice of the control parameters $K$ and $L$ in order to ensure the stealthiness of the digital communication system being developed with chaotic subcarriers should be made in such a way as to ensure the maximum similarity of the parameters and characteristics of the signals in the transmission line.

\section{TELECOMMUNICATION SYSTEM USING GENERALIZED SYNCHRONIZATION}

\subsection{Research Problem}

In the construction of telecommunication systems based on chaos oscillators, there are a number of problems that complicate their practical implementation and synchronization, including:

- high sensitivity of secondary system parameters to the accuracy and stability of composite elements;

- the need to use chaotic synchronization and chaotic synchronous response to ensure the correct operation of the system on the receiving and transmitting side of the communication line;

- the nature of the interference effect on chaotic communication systems is significantly different from the interference effect on linear systems.

To solve the research problems, modelling is reasonable to be carried out in the aspects of determining the optimal values of the NDS control parameters and their synchronization system under the condition of interference.

\subsection{The Principle of Transmitting Digital Signals Using NDS}

Under the conditions of a digital modulating message, the most acceptable method for practical implementation is the method of receiving chaotic signals, based on the use of parallel auxiliary NDS. The essence of the method consists in the introduction parallel to the receiving unit on the basis of a chaotic oscillator of an additional block identical in structure.

The essence of digital level transmission in the described system of two slave oscillators and one master oscillator is to introduce a unidirectional connection from the master oscillator to the slaves of such a level that it would be possible to capture the chaotic behaviour of the master oscillator by the slaves under given initial conditions. The transition from chaotic synchronization of slave oscillators to desynchronization should have a pronounced threshold for the possibility of effectively separating the logical levels of the digital information message. After the "capture" of the behaviour of the driven oscillators, regardless of the differences their parameters, 
the difference between the state vectors of the driven chaotic oscillators is minimal.

On the contrary, in the case of setting the driving parameters of the master oscillator in the desynchronization zone, the master oscillator is not capable of "imposing" its chaotic mode to the slave. As a result of this fact, each of the slaves operates autonomously and, owing to chaotic behaviour, their phase trajectories exponentially spread out, which leads to a large difference between their state vectors. Thus, the digital modulation of the control parameter values makes it possible to transmit two digital levels using the presence and absence of generalized synchronization between chaotic pairs of the master-slave oscillator.

Such a logic level transfer scheme eliminates the problem of a high initial identity of the control pairs of the parameters between the slave and the master oscillators that are spaced apart in space.

Unidirectional communication between slave and master oscillators is introduced by means of a nonreciprocal adder of two channels with a total unit transmission coefficient (1). The first channel provides internal communication over one of the possible state variables of the oscillator with a transmission coefficient $b$, where $0<b<1$, the second channel provides transmission of a synchronizing signal from the master oscillator with a coefficient transfer of $(1-b)$. Only such a way, at provided complete identity of all oscillators, the difference between their state vectors is zero.

The fact of the presence or absence of generalized synchronization during the transmission of a certain digital level is fixed by analysing the differences in the state vectors of the slave oscillators. Such an analysis can be conducted according to different criteria, the most popular of which is the mean square error of reception in the transmission interval of one bit. The differences in the reception error between the signals of the two slave oscillators during the logical zero and the logical one transmission determine the reception margin when identifying logical levels, which in turn determines the noise immunity of the system as a whole.

\subsection{Transmission System Model}

The mathematical model of the system of three connected Rucklidge oscillators, which are the basis of a chaotic communication system, based on the principle of identifying chaotic synchronization with the help of an auxiliary NDS, is as follows:

$$
\left\{\begin{array}{l}
\frac{d x_{m 1}}{d t}=-K_{m 1} \cdot x_{m 1}+L_{m 1} \cdot y_{m 1}-y_{m 1} \cdot z ; \frac{d y_{m 1}}{d t}=x_{m 1} ; \frac{d z_{m 1}}{d t}=-z+y_{m 1}^{2} \\
\frac{d x_{s 1}}{d t}=-K_{s 1} \cdot x_{s 1}+L_{s 1} \cdot\left(y_{m 1} \cdot(1-b)+y_{s 1} \cdot b\right)-\left(y_{m 1} \cdot(1-b)+y_{s 1} \cdot b\right) \cdot z_{s 1} \\
\frac{d y_{s 1}}{d t}=x_{s 1} ; \frac{d z_{s 1}}{d t}=-z_{s 1}+\left(y_{m 1} \cdot(1-b)+y_{s 1} \cdot b\right)^{2} ; \\
\frac{d x_{s 2}}{d t}=-K_{s 2} \cdot x_{s 2}+L_{s 2} \cdot\left(y_{m 1} \cdot(1-b)+y_{s 2} \cdot b\right)-\left(y_{m 1} \cdot(1-b)+y_{s 2} \cdot b\right) \cdot z_{s 2} \\
\frac{d y_{s 2}}{d t}=x_{s 2} ; \frac{d z_{s 2}}{d t}=-z_{s 2}+\left(y_{m 1} \cdot(1-b)+y_{s 2} \cdot b\right)^{2}
\end{array}\right.
$$


where $x_{m 1}, y_{m 1}, z_{m 1}$ - the state vector (phase coordinates) of the master oscillator;

$x_{s 1}, y_{s 1}, z_{s 1}$ - the state vector of the main slave oscillator;

$x_{s 2}, y_{s 2}, z_{s 2}$ - the state vector of the auxiliary slave oscillator.

As criteria for identifying the presence of generalized synchronization between chaotic oscillators, two different similarity criteria were used during the simulation.

The standard deviation criterion $\delta_{1}$ and criterion of the average rectified deviation $\delta_{2}$ are often used to determine the reception error in analogue communication systems:

$$
\delta_{1}=\frac{1}{N} \sum_{i=1}^{N}\left(u_{i}-v_{i}\right)^{2} ; \quad \delta_{2}=\frac{1}{N} \sum_{i=1}^{N}\left|u_{i}-v_{i}\right|,
$$

where $u_{i}, v_{i}$-phase coordinates of the main and additional slave oscillator, respectively; $N$ - the sample size taken for analysis.

$$
\Delta_{1}=\frac{\delta_{1 " 0 "}}{\delta_{1 " 1 "}} ; \quad \Delta_{2}=\frac{\delta_{2 " 0 "}}{\delta_{2 " 1 "}} .
$$

The ratio of the values of the criteria above for the desynchronization mode (transfer $\log$ " 0 ") and for the synchronization mode (transfer log " 1 ") determines the value of the noise margin and the possibility to identify logical levels correctly.

\subsection{Simulation Results}

Confirmation of the presence or absence of synchronization during the transmission of logic levels can be visually assessed by analysing the attractors of the slave oscillators in the presence of interference in the communication line (Fig. 2). When synchronizing (log "1"), the attractor of the slave oscillator (Fig. 2, left) has a strongly pronounced two-loop structure and is concentrated in a limited volume of the phase space. In the mode of desynchronization ( $\log$ " 0 "), the attractor starts to fill the phase space evenly and increases its swing (Fig. 2, right).
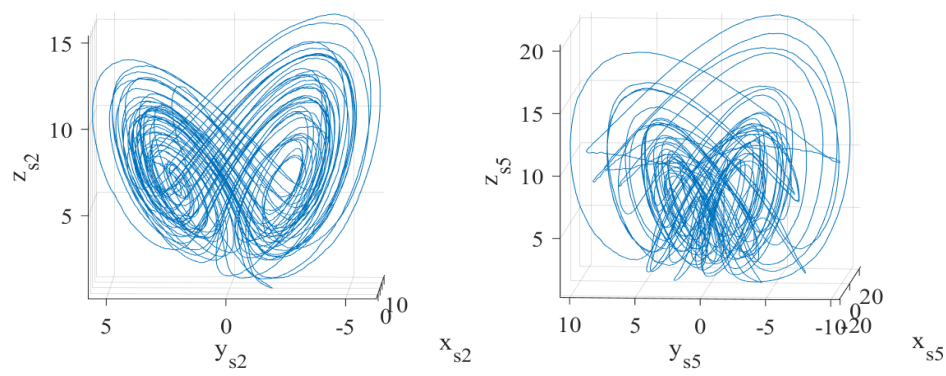

Fig. 2. The attractor of one of the slave oscillators during synchronization (left) and at desynchronization (right) with $\mathrm{SNR}=10$. 
Using the visual criteria (Fig. 2), the most optimal control parameter groups of the slave and master oscillators are identified according to the criteria of maximum similarity in the spectral unevenness, effective value and mutual correlation properties.

The main attention during modelling was given to the possibility of the transmission system operation under conditions of a significant level of interference. In most proposed transmission systems based on chaotic subcarriers, the minimum achievable SNR does not exceed 30-40 dB.
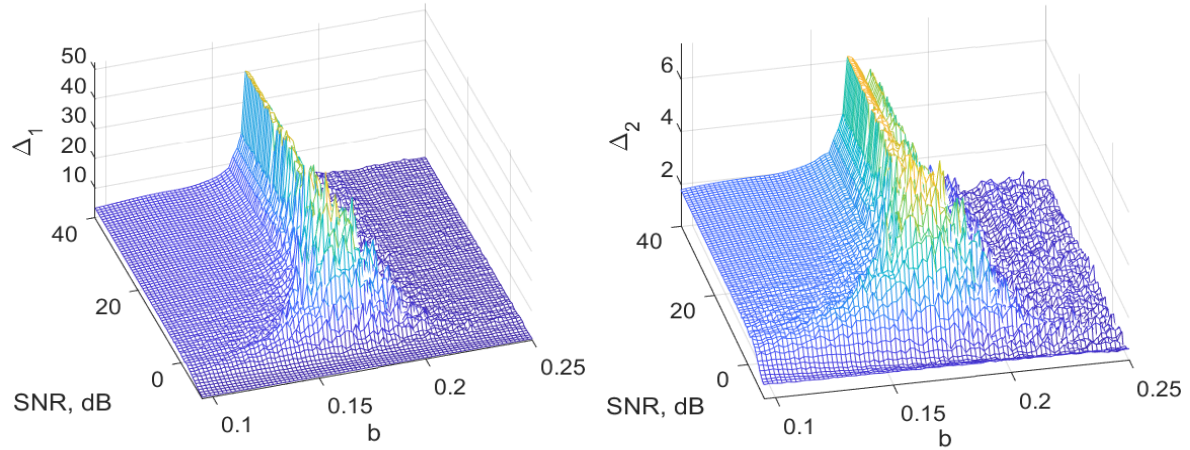

Fig. 3. Dependence of mean square (left) and average rectified (right) deviation on the communication parameter and SNR, dB.

The results of mathematical modelling of the proposed system, the maximization of values by the criterion of mean square $\delta_{1}$ and average rectified values $\delta_{2}$ showed the presence of considerable stability of the system to interference. System performance was ensured at SNR level $>0 \mathrm{~dB}$, under the condition of values of the coupling parameter of chaotic oscillators $0.13<b<0.18$ (Fig. 3). Thus, the possibility of transmitting digital information is confirmed, when interference level in the signal is commensurable with the level of the signal, which allows us to call such a transmission scheme superstable to noise.

\section{CONCLUSIONS}

A telecommunication system for the transmission of digital signals using the Rucklidge oscillator signals as subcarriers has been proposed in the research. A number of criteria for testing the quality characteristics of the system synchronization under interference conditions have also been proposed in the paper.

The simulation of the proposed data transmission system has been carried out, as a result of which the values of control parameters, communication parameters and interference level have been established, which ensure digital information transmission with the maximum degree of action reliability and concealment.

The use of the advantages of ultra-wideband chaotic signals in a data transmission system based on the implemented synchronization method has the prospect of being used to transmit information in various industries such as electric transport, automobile industry, railway industry etc., which have high noise immunity requirements due to a large number of electromagnetic radiation sources. 
The research leading to these results has been supported by the European Regional Development Fund project "Development of Competence Centre of Mechanical Engineering”, contract No.1.2.1.1/16/A/003 signed between the Competence Centre of Mechanical Engineering and Central Finance and Contracting Agency, Research No. 3.2. "Dual Fuel System Development for a Diesel Engine Locomotive".

\title{
REFERENCES
}

1. Andronov, A.A. (1988). To the mathematical theory of capture. Magazine of Applied Physics, 7, 3-11.

2. Koronovsky, A.A. (2009). About the application of chaotic synchronization for the hidden transmission of information. Uspekhi Fizicheskikh Nauk, 12, 1281-1310.

3. Volkovsky, A.R., \& Rulkov, N.F. (1993). Synchronous chaotic response of a non-linear information transfer system with a chaotic carrier. Letters in ZhTF, 19(3), 71.

4. Anishchenko, V.S. (1992). Synchronization of chaos. Int. J. of Bifurcation and Chaos., 2(3), 633-644.

5. Bellman, R. (1969). Introduction to matrices theory. M: The science.

6. Golevich, O.B. (2014). The method of matching chaotic signals to be used in ultrabroadband communication systems. Measuring and Computing Equipment in Technological Processes, 3, 173-175.

7. Golevich, O.B. (2015). Chaotic signals ensembles order and the way to use them in ultrabroadband communication systems. Digital Technologies, 17, 181-191.

8. Pehlivan, İ., Uyaroğlu, Y., \& Yoğun, M. (2010). Chaotic oscillator design and realizations of the rucklidge attractor and its synchronization and masking simulations. Scientific Research and Essays, 16, 2210-2219.

\section{NELINEĀRO DINAMISKO SISTĒMU SINHRONIZĀCIJA TROKŠŅU DARBĪBAS APSTĀKḶOS KANĀLĀ}

\author{
O.Golevych, O.Pyvovar, P.Dumenko
}

\section{Kopsavilkums}

Ir paveikta dinamiskās sistēmas Rucklidge analīze un noteiktas vērtības vadības parametriem, kas nodrošina digitālās informācijas nodošanu ar maksimālu ticamības pakāpi un darbības slepenību. Balstoties uz izstrādāto sinhronizācijas veidu, ierosināts izveidot digitālo signālu pārraides telekomunikācijas sistēmu, izmantojot ǵeneratora Rucklidge signālus.

23.05.2018. 